\title{
Evaluation of Pre-Clinical Efficacy to HPV16 L2E6E7 Vaccine and HPV16 E6E7 Adenovirus-5 Vector Vaccine with Different Dosages and Prime- Booster Regiments in Mouse Model
}

Zhuang Fang-Cheng ${ }^{1,2 *}$, Chen Gang ${ }^{1}$, Wu Jie ${ }^{2}$, Jin Su-feng ${ }^{2}$, Jiang Yun-shui ${ }^{1}$, Gao Men ${ }^{1}$, Li Jian-buo ${ }^{3}$, Zhao Li ${ }^{4}$, Mao Zian ${ }^{3}$ and Tian Houwen ${ }^{4}$ ${ }^{1}$ Institute of Viral Diseases, Zhejiang Academy of Medical Sciences, Hangzhou, P.R. China

${ }^{2}$ Zhejiang Key Laboratory of Bio-medical Vaccine R and D, Hangzhou, P.R. China

${ }^{3}$ Zhejiang Pukang Biotechnology Co., Ltd., Hangzhou, P.R. China

${ }^{4}$ Institute of Viral Disease Prevention and Control, National Centre for Diseases Prevention \& Control, Beijing, P.R. China

\begin{abstract}
Purpose: This study evaluates the dose-response and immunization procedure in mouse model and the efficacy of prime-booster regimens with HPV16 L2E6E7 vaccine and HPV16 E6E7 Ad5 vector vaccine. Methods: Experimental animals were C57 BL/6 mice. Each group included 10 or 20 C57 BL/6 mice. The tumor model used TC-1 tumor cells. The HPV16 L2E6E7 vaccine groups were treated using the following dosage: $15 \mu \mathrm{g} / \mathrm{ml}, 30 \mu \mathrm{g} / \mathrm{ml}, 60 \mu \mathrm{g} / \mathrm{ml}$, $120 \mu \mathrm{g} / \mathrm{ml}, 240 \mu \mathrm{g} / \mathrm{ml}$, and then $120 \mu \mathrm{g} / \mathrm{ml}$ was used for the following regimens: 0-7 days, 0-15 days, 0-7-15 days. The HPV16 E6E7 Adenovirus-5 vector vaccine groups were treated using the following dosage: $3.00 \times 10^{6} \mathrm{IU} / \mathrm{ml}$, $3.00 \times 10^{7} \mathrm{IU} / \mathrm{ml}, 3.00 \times 10^{8} \mathrm{IU} / \mathrm{ml}, 3.00 \times 10^{9} \mathrm{IU} / \mathrm{ml}$, and then $3.00 \times 10^{7} \mathrm{IU} / \mathrm{ml}$ was used for the following regimens: $0-7$ days, 0-15 days, 0-7-15 days, and control group. Prime-booster combined regimens with HPV L2E6E7 vaccine $(P$, $120 \mu \mathrm{g} / \mathrm{ml})$ and HPV16 E6E7 ad5 vector vaccine $\left(\mathrm{V}, 3.00 \times 10^{7} \mathrm{IU} / \mathrm{ml}\right)$ were set as follows: OP-7P days, 0P-7V days, and OP-7P-15V days, OP-7V-15V days, and OP-7P-15V-21V days.
\end{abstract}

Results: Upon challenge with $10^{4} \mathrm{TC}-1$ tumor cells, mice developed palpable, rapidly growing tumors within 7-14 days. These tumors became lethal to the mice within 21-28 days. HPV16 L2E6E7 vaccine (120 $\mu \mathrm{g} / \mathrm{ml}, 0-7$ 15 day's procedure) protective efficacy was $85 \%$ and the HPV16 E6E7 Ad5 vector vaccine $\left(3.00 \times 10^{7}\right.$ IU/ml, 0 day procedure) that was $80 \%$. Prime-booster regimens showed a protective efficacy of $80-90 \%$ for the $0 \mathrm{P}-7 \mathrm{~V}$ days and OP-7V-15V day's schedules. Conclusion: HPV16 L2E6E7 vaccine and HPV16 E6E7 Ad5 vector vaccine are proved the candidate vaccine for therapeutic intervention against HPV16-induced tumor.

Keywords: Human papillomavirus-16; Therapeutic vaccine; Preclinical; Efficacy

\section{Introduction}

Vulval intraepithelial neoplasia (VIN) and cervical cancer are commonly associated with human papillomavirus (HPV) type 16 infection $[1,2]$. This discovery has provided the opportunity for an immunotherapeutic approach to the treatment of these conditions. HPV infection by one or more "high-risk" or "oncogenic" types, most commonly 16 and 18 , are present in $90-100 \%$ of invasive and grade 3 intraepithelial cervical lesions and in the majority of noncervical anogenital neoplasias. HPV oncogenes E6 and E7 play a crucial role in lower genital tract carcinogenesis and are required for maintenance of the transformed state and malignant phenotype $[3,4]$. This makes the HPV16 E6 and E7 oncoproteins attractive targets for immunotherapy because they are exclusively expressed in virally infected and neoplastic cells, never in normal or healthy cells.

An alternative approach is to induce systemic cell-mediated immune responses with the aim of effecting local cytotoxicity against the virus infected cells. Nonreplicating recombinant adenoviruses have been shown to induce cell-mediated and humoral immune responses and, in some cases, protection against a variety of pathogens $[5,6]$. A recombinant HPV 16-L2E6E7 fusion protein (HPV16 P-vaccine) and adenovirus 5 vector delivered HPV E6E7 protein (HPV16 Ad5vaccine) were built using pilot plant technology. In order to develop the therapeutic vaccine, we need to evaluate the dose-response and immunization procedure in mouse model and the efficacy of primebooster regimens. Only then can we seek permission from the China's FDA to perform clinical trials.

\section{Methodology}

Antigens and vaccine formulations: HPV16 P-vaccine, a recombinant HPV 16-L2E6E7 fusion protein, was isolated from solubilized E. coli inclusion bodies under reducing conditions and purified by chromatography. The $80 \mathrm{kD}$ L2E6E7 monomer comprises 725 amino acids, as predicted by the nucleotide sequence of the L2E6E7 gene. The protein was formulated using $5 \mathrm{mM}$ glycine buffer $(\mathrm{pH} \mathrm{8.0)}$ containing $0.9 \mathrm{mM}$ cysteine and finally freeze-dried and routinely stored at $2-8^{\circ} \mathrm{C}$ until use. Prior to administration of the vaccine protein, $0.5 \mathrm{ml}$ sterile water was added for injection. The final vaccine consisted of a white homogeneous liquid.

HPV16 Ad5-vaccine, adenovirus 5-vector-delivered HPV E6E7 protein, consisted of the fused E6 and E7 open reading frames of HPV16, each under the control of an adenovirus promoter. The fused E6 and E7 genes had previously been found to show no transforming activity. The virus was prepared at a concentration of $1 \times 10^{8}$ infective units $(\mathrm{IU}) / \mathrm{ml}$. HPV16 Ad5-vaccine is routinely stored at $-70^{\circ} \mathrm{C}$ until use.

Experimental animal and tumor model establishment: C57 BL/6

*Corresponding author: Zhuang Fangcheng, Institute of Viral Diseases, Zhejiang Academy of Medical Sciences, Hangzhou 310013, China, Tel: +86 57188861601 ; Fax: +86 571 89890270; E-mail: fczhuang@163.com

Received June 13, 2013; Accepted June 24, 2013; Published June 28, 2013

Citation: Fang-Cheng Z, Gang C, Jie W, Su-feng J, Yun-shui J, Men G, et al. (2013) Evaluation of Pre-Clinical Efficacy to HPV16 L2E6E7 Vaccine and HPV16 E6E7 Adenovirus-5 Vector Vaccine with Different Dosages and Prime-Booster Regiments in Mouse Model. J Vaccines Vaccin 4: 189. doi:10.4172/21577560.1000189

Copyright: $(2013$ Fang-Cheng Z, et al. This is an open-access article distributed under the terms of the Creative Commons Attribution License, which permits unrestricted use, distribution, and reproduction in any medium, provided the original author and source are credited. 
Citation: Fang-Cheng Z, Gang C, Jie W, Su-feng J, Yun-shui J, Men G, et al. (2013) Evaluation of Pre-Clinical Efficacy to HPV16 L2E6E7 Vaccine and HPV16 E6E7 Adenovirus-5 Vector Vaccine with Different Dosages and Prime-Booster Regiments in Mouse Model. J Vaccines Vaccin 4: 189. doi:10.4172/2157-7560.1000189

Page 2 of 4

mice (female, 6-8 weeks, 20-25 g) were obtained from Shanghai SLAC Laboratory Animal Center and held under specific pathogenfree conditions. All experiments in C57 BL/6 mice were performed in compliance with "Experimental Animal Management Regulations in Zhejiang Province, China”.

TC-1 tumor cells derived from primary epithelial cells of C57 $\mathrm{BL} / 6$ mice were co-transformed with HPV16 E6 and E7 and c-Ha-ras oncogenes. These cells were cultured in IMDM $+10 \%$ FCS.

C57 BL/6 mice were injected subcutaneously with $1 \times 10^{4} \mathrm{TC}-1$ cells in the left leg, and were vaccinated with HPV 16 P-vaccine next day (recorded as day 0, 24 hours later after injection TC-1 cells) according to the dosage strategies selected for that mouse's treatment group. Control group mice were injected only with the freeze-dried formulizer.

HPV-specific cellular immunity and tumor development were monitored from day 7 through day 40, until the tumor growth remained stable through three consecutive observations. At that point mice were killed.

Different groups of mice were immunized at different dosages and on different regimens: HPV16 p-vaccine for dose-response groups was set as follows: $15 \mu \mathrm{g} / \mathrm{ml}, 30 \mu \mathrm{g} / \mathrm{ml}, 60 \mu \mathrm{g} / \mathrm{ml}, 120 \mu \mathrm{g} / \mathrm{ml}, 240 \mu \mathrm{g} / \mathrm{ml}$, and a control group (amino-salt formulizer). Based on the dose-responses results, different immunization procedures were established: $120 \mu \mathrm{g} / \mathrm{ml}$ on days 0 and 7 (0-7), on days 0 and 15 (0-15), on days 7 and 15 (7-15), and on days 0,7 , and 15 (0-7-15), and a control group (also at 0-7-15). Each group included 10 or $20 \mathrm{C} 57 \mathrm{BL} / 6$ mice.

HPV16 Ad5-vaccine for dose-response groups was set as follows: $3.00 \times 10^{6} \mathrm{IU} / \mathrm{ml}, 3.00 \times 10^{7} \mathrm{IU} / \mathrm{ml}, 3.00 \times 10^{8} \mathrm{IU} / \mathrm{ml}$, and $3.00 \times 10^{9} \mathrm{IU} / \mathrm{ml}$, with control group (ad5+PBS). Based on the dose-response results, different immunization procedures were established: $3.00 \times 107 \mathrm{IU} / \mathrm{ml}$ at 0-7, 0-15, and 0-7-15, and a control group (Ad5, 0-7-15).

Combined prime-booster regimens with HPV p-vaccine (marked $\mathrm{P}$ ) and HPV ad5-vaccine (marked V) were set as follows: 0P-7P, 0P7V, 0P-7P-15V, 0P-7V-15V, and 0P-7P-15V-21V with $120 \mu \mathrm{g} / \mathrm{ml} \mathrm{HPV}$ p-vaccine and $3.00 \times 10^{7} \mathrm{IU} / \mathrm{ml} \mathrm{HPV}$ ad5-vaccine.

Observation index: onset of the tumor, size of the tumor; tumor outgrowth rate $=$ No. of mice shown the tumor /No. of mice in group; efficacy $(\%)$ = tumor outgrowth (\%) in control group - tumor out growth (\%) in vaccine group.

\section{Results}

1. HPV p-vaccine. Upon challenge with $10^{4} \mathrm{TC}-1$ cells, mice developed palpable, rapidly growing tumors within 7-14 days. These became lethal to the mice within 21-28 days. As such, newly challenged mice were regarded as a proper model for immune-intervention against minimal residual disease. Mice challenged with $10^{4}$ TC- 1 cells were vaccinated 24 hours after of challenge (on day 0 ) and monitored for the development of the tumors. All control mice quickly developed tumors. Therapeutic vaccination with $120 \mu \mathrm{g} / \mathrm{ml} \mathrm{HPV} \mathrm{p-vaccine}$ on a $0-7-15$ schedule protected the majority of mice against tumor outgrowth (19/20). The onset of tumor growth in one tumor-positive mouse was delayed ( 21 days after challenge). The protective effect of $15 \mu \mathrm{g} / \mathrm{ml}$ and $30 \mu \mathrm{g} / \mathrm{ml}$ was considerable weaker. Dosages of HPV16 p-vaccine at $60 \mu \mathrm{g} / \mathrm{ml}, 120 \mu \mathrm{g} / \mathrm{ml}$, and $240 \mu \mathrm{g} / \mathrm{ml}$ showed an efficacy of $40 \%, 60 \%$, and $60 \%$ respectively. The most effective immunization regimen was the 0-7-15 schedule at a dosage of $120 \mu \mathrm{g} / \mathrm{ml}$ (Figures 1 and 2). Taken together, these results show that HPV p-vaccine administrated at a dose of $120 \mu \mathrm{g} / \mathrm{ml}$ on a $0-7-15$ schedule is highly effective $85 \%$ in therapeutic settings.

2. HPV16 Ad5-vaccine. All control mice quickly developed tumors within 7-14 days. The onset of tumor growth in the HPV ad5-vaccine group was delayed for 14 days after challenge (Figure 3 ). The dose of $3.00 \times 10^{7} \mathrm{IU} / \mathrm{ml}$ showed $80 \%$ efficacy whereas both $3.00 \times 10^{8} \mathrm{IU} / \mathrm{ml}$ and $3.00 \times 10^{9} \mathrm{IU} / \mathrm{ml}$ showed $100 \%$ efficacy. Single doses of $3.00 \times 10^{7} \mathrm{IU} / \mathrm{ml}$ or more were so highly effective, there was no significant difference between the different immunization schedules. Therapeutic vaccination with HPV ad5-vaccine at single doses of $3.00 \times 10^{7} \mathrm{IU} / \mathrm{ml}$ or more was found to protect the majority of mice from tumor outgrowth.

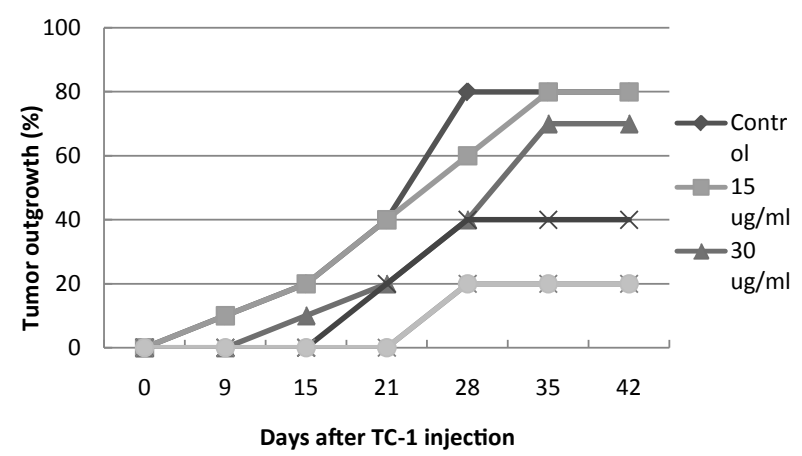

Figure 1: Each group consists of $10 \mathrm{C} 57 \mathrm{BL} / 6$ mice. HPV-p vaccine with different dosage groups was designed as $15 \mathrm{ug} / \mathrm{ml}, 30 \mathrm{ug} / \mathrm{ml}, 60 \mathrm{ug} / \mathrm{ml}, 120$ $\mathrm{ug} / \mathrm{ml}$ and $240 \mathrm{ug} / \mathrm{ml}$; control group was injected with amino-salt formulizer.

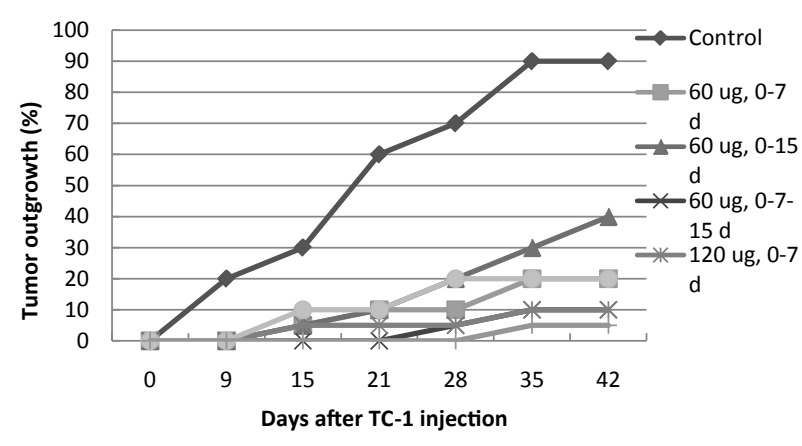

Figure 2: Each group consists of $20 \mathrm{C} 57 \mathrm{BL} / 6$ mice. HPV-p vaccine in different immunization procedure were designed as 0-7 days, 0-15 days, $0-7-15$ days injection the vaccine with dosage of $60 \mathrm{ug} / \mathrm{ml}$ and $120 \mathrm{ug} / \mathrm{ml}$ respectively; control group was injected with amino-salt formulizer.

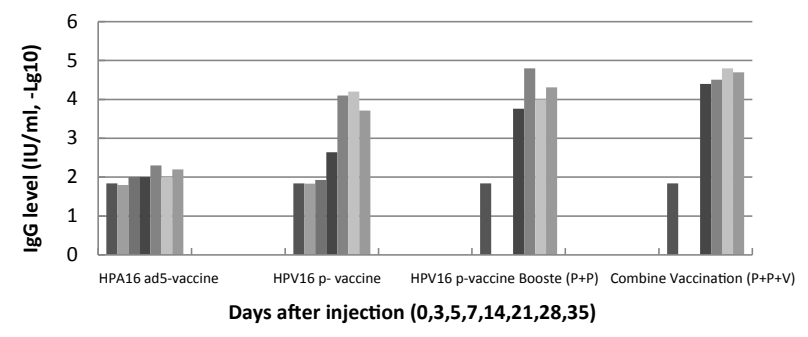

Figure 3: Each group consists of $10 \mathrm{C} 57 \mathrm{BL} / 6$ mice. HPV ad5-vaccine in different dosage were designed as $3 \times 10^{4} \mathrm{iu} / \mathrm{ml}, 3 \times 10^{5} \mathrm{iu} / \mathrm{ml}, 3 \times 10^{6} \mathrm{iu} / \mathrm{ml}, 3 \times 10^{7}$ $\mathrm{iu} / \mathrm{ml}, 3 \times 10^{8} \mathrm{iu} / \mathrm{ml}$ and $3 \times 10^{9} \mathrm{iu} / \mathrm{ml}$; Control group was injected with adv5+PBS. 
Citation: Fang-Cheng Z, Gang C, Jie W, Su-feng J, Yun-shui J, Men G, et al. (2013) Evaluation of Pre-Clinical Efficacy to HPV16 L2E6E7 Vaccine and HPV16 E6E7 Adenovirus-5 Vector Vaccine with Different Dosages and Prime-Booster Regiments in Mouse Model. J Vaccines Vaccin 4: 189. doi:10.4172/2157-7560.1000189

Page 3 of 4

3. Monitoring of vaccine induced immunoresponses. The number of T-cells per 300,000 splenocytes that spontaneously appeared following stimulation with E749-57 peptide produced IFN-r upon stimulation was not found to be significant. No such cells were detected by ELISPOT, but ELISA showed HPV16-specific IgG antibodies to be present at a high titer in the sera of the mice (Figure 4). In the different regimens, the results showed that only HPV ad5-vaccine failed to significantly increase IgG levels. The HPV p-vaccine was significantly associated with increases in IgG. The combined regimens with p-vaccine boosted with p-vaccine or with ad5-vaccine showed highly increased IgG levels.

4. Prime-boost regimens with HPV p-vaccine and HPV ad5vaccine. In control groups, the greatest frequency of tumor onset was observed from day 7 through day 14 . Our results showed that injection of HPV ad5-vaccine at day 7 was more efficacious at suppressing tumor outgrowth than injections of HPV p-vaccine. Heterologous primebooster immunization regimens, in which two different types of vaccine sharing the antigen of choice are used, have been proven more effective in stimulating the $\mathrm{T}$-cell responses than homologous immunization regimens. Our experiment demonstrated that heterologous regimen works as well or better when HPV ad5-vaccine is administered in a single dose of $3.00 \times 10^{7} \mathrm{IU} / \mathrm{ml}$. Regimens $0 \mathrm{P}-7 \mathrm{~V}$ and $0 \mathrm{P}-7 \mathrm{~V}-15 \mathrm{~V}$ showed strong protective efficacy against tumor outgrowth, with an efficacy of $80-90 \%$ (Figure 5).

\section{Discussion}

Over the past decade, substantial progress has been made in the

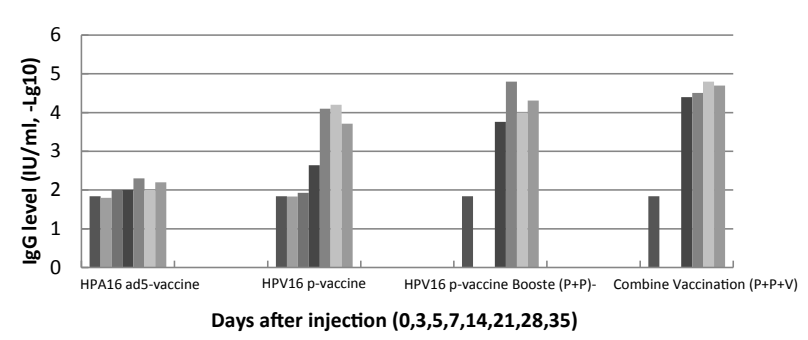

Figure 4: HPV p-vaccine at dosage of $120 \mathrm{ug} / \mathrm{ml}$ and HPV ad5-vaccine at dosage of $3 \times 10^{7} \mathrm{iu} / \mathrm{ml}$; Groups were designed as $A=\mathrm{HPV}$ ad5 vaccine 1 dose injection at 0 day, $B=H P V$ p-vaccine 1 dose injection at 0 day, $C=H P V$ $p$-vaccine injection at 0,7 days, $D=H P V$-vaccine injection at 0,7 days and HPV ad5-vaccine injection at 14 day. Serum test IgG level use the ELISA.

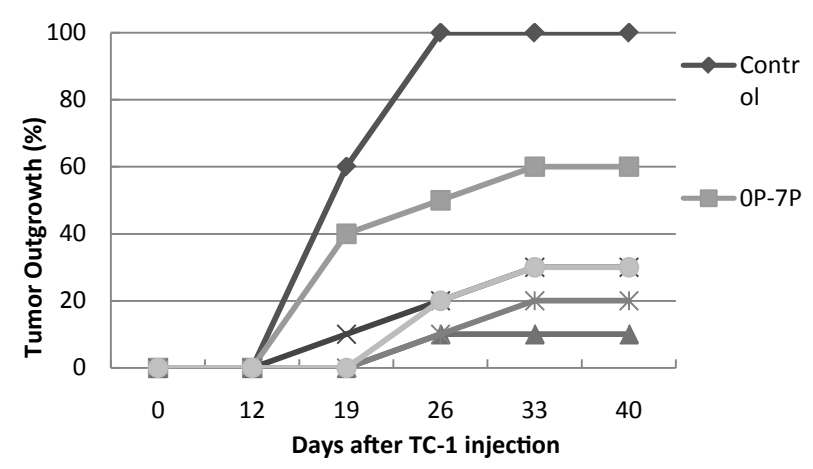

Figure 5: Each group consists of $10 \mathrm{C} 57 \mathrm{BL} / 6$ mice. HPV p-vaccine dosage of $120 \mathrm{ug} / \mathrm{ml}$ and HPV ad5-vaccine dosage of $3 \times 10^{7} \mathrm{iu} / \mathrm{ml}$, at the different combined procedure; $\mathrm{OP}=$ Injection $\mathrm{HPV} p$-vaccine at 0 day, $7 \mathrm{P}=$ =njection HPV $\mathrm{p}$-vaccine at 7 day, $7 \mathrm{~V}=$ =njection HPV ad5-vaccine at 7 day, $15 \mathrm{~V}=$ Injection HPV ad5-vaccine at 15 day and $21 \mathrm{~V}=$ Injection HPV ad5-vaccine at 21 day; Control group was injected with amino-salt formulizer. understanding of host immune responses to HPV infection and in the development of candidate vaccines [7]. The rationale behind immunotherapy for intraepithelial neoplasia is based upon the expression of HPV E6 and E7 proteins, which distinguish neoplastic from normal epithelia, thereby acting as tumor-specific antigens [8]. Animal model experiments have demonstrated that the induction of E6- and E7-specific T cells can effectively control established tumors, and several candidate vaccines are being tested in early-phase clinical trials $[9,10]$.

We here evaluated therapeutic HPV p-vaccine, and HPV ad5vaccine in a pre-clinical mouse model. Our data show that the majority of mice were protected against tumor outgrowth when HPV p-vaccine and HPV ad5-vaccine were therapeutically administered in a setting of minimal residual disease. For the HPV p-vaccine, INF-r was not significantly induced, but the levels of the specific antibody IgG were found to be highly increased after vaccination. This differs from the findings of some other research teams [11].

The viral vector in therapeutic HPV vaccine as reported was a vaccinia virus-based vaccine TA-HPV, which has been tested in cervical cancer patients $[12,13]$. In our research, we used the adenovirus-5 vector carrying the HPV 16 E6/E7 fusion proteins. The results indicated that HPV ad5-vaccine at a dose of $3.00 \times 10^{7} \mathrm{IU} / \mathrm{ml}$ or more, even when only a single dose was administered protected $80 \%$ of the mice from tumor outgrowth. This suggests that it is possible for viral vector vaccines to use vaccinia virus and adenovirus- 5 as vectors. Both of these showed the same efficacy in the mouse model.

The HPV ad5-vaccine, developed through pre-clinical mouse studies, was found to be capable of inducing substantial numbers of specific CTL $[14,15]$. In this study we did not find any significantly increased levels of INF-r of CTL. In the prime-booster regimens HPV p-vaccine combined with HPV ad5-vaccine demonstrated greater efficacy than all other single or homologous strategies.

The prime-boost regimens with HPV p-vaccine and HPV ad5vaccine showed the greatest ability to protect mice from tumor outgrowth, at about $80-90 \%$. These results provide a scientific basis for the evaluation of HPV p-vaccine and HPVad5-vaccine in human trials for therapeutic intervention against HPV16-induced disease.

\section{Acknowledgement}

Our thanks to the government funding supports: Grant from Zhejing Science and Technology Bureau for Key Lab of vaccine R and D. Grant No.: 2008F3022 and Hangzhou City Science and Technology Bureau for High-tech Create Project. Grant No: 20112313A37].

\section{References}

1. Jones RW (2001) Vulval intraepithelial neoplasia: current perspectives. Eur J Gynaecol Oncol 22: 393-402.

2. Mc Nally OM, Mulvany NJ, Pagano R, Quinn MA, Rome RM (2002) VIN 3: a clinicopathologic review. Int J Gynecol Cancer 12: 490-495.

3. Palefsky JM, Holly EA (1995) Molecular virology and epidemiology of human papillomavirus and cervical cancer. Cancer Epidemiol Biomarkers Prev 4: 415-428.

4. Crook T, Morgenstern JP, Crawford L, Banks L (1989) Continued expression of HPV-16 E7 protein is required for maintenance of the transformed phenotype of cells co-transformed by HPV-16 plus EJ-ras. EMBO J 8: 513-519.

5. Michael B, Julie D, Egbert H (2005) Variable adenovirus vaccine prototypes: High-level production of a papillomavirus capsid antigen from the majority late transcriptional unit. PNAS 102: 4590-4595.

6. Borysiewicz LK, Fiander A, Nimako M, Man S, Wilkinson GW, et al. (1996) A recombinant vaccinia virus encoding human papillomavirus types 16 and 18 , 
Citation: Fang-Cheng Z, Gang C, Jie W, Su-feng J, Yun-shui J, Men G, et al. (2013) Evaluation of Pre-Clinical Efficacy to HPV16 L2E6E7 Vaccine and HPV16 E6E7 Adenovirus-5 Vector Vaccine with Different Dosages and Prime-Booster Regiments in Mouse Model. J Vaccines Vaccin 4: 189. doi:10.4172/2157-7560.1000189

E6 and E7 proteins as immunotherapy for cervical cancer. Lancet 347: 15231527.

7. Stanley M. Immune responses to human papillomaviruses. London, UK: Arnold 2001: 38-49.

8. Gilboa $E$ (1999) The makings of a tumor rejection antigen. Immunity 11: 263270 .

9. Bethwaite PB, Holloway LJ, Thornton A, Delahunt B (1996) Infiltration by immunocompetent cells in early stage invasive carcinoma of the uterine cervix: a prognostic study. Pathology 28: 321-327.

10. Liu DW, Tsao YP, Hsieh CH, Hsieh JT, Kung JT, et al. (2000) Induction of CD8 $T$ cells by vaccination with recombinant adenovirus expressing human papillomavirus type 16 E5 gene reduces tumor growth. J Virol 74: 9083-9089.

11. Todd RW, Etherington IJ, Luesley DM (2002) The effects of $5 \%$ imiquimod cream on high-grade vulval intraepithelial neoplasia. Gynecol Oncol 85: 67-70.
12. Boursnell ME, Rutherford E, Hickling JK, Rollinson EA, Munro AJ, et al. (1996) Construction and characterisation of a recombinant vaccinia virus expressing human papillomavirus proteins for immunotherapy of cervical cancer. Vaccine 14: $1485-1494$.

13. Borysiewicz LK, Fiander A, Nimako M, Man S, Wilkinson GW, et al. (1996) A recombinant vaccinia virus encoding human papillomavirus types 16 and 18 E6 and E7 proteins as immunotherapy for cervical cancer. Lancet 347: 15231527.

14. van der Burg SH, Kwappenberg KM, O'Neill T, Brandt RM, Melief CJ, et al. (2001) Pre-clinical safety and efficacy of TA-CIN, a recombinant HPV16 L2E6E7 fusion protein vaccine, in homologous and heterologous prime-boost regimens. Vaccine 19: 3652-3660.

15. Liu DW, Tsao YP, Hsieh CH, Hsieh JT, Kung JT, et al. (2000) Induction of CD8 $\mathrm{T}$ cells by vaccination with recombinant adenovirus expressing human papillomavirus type 16 E5 gene reduces tumor growth. J Virol 74: 9083-9089. 